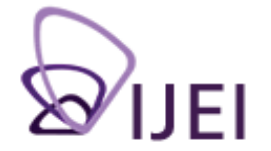

\author{
International \\ Journal for \\ Educational \\ Integrity
}

\title{
Students' research ethics competences and the university as a learning environment
}

\author{
Minka Rissanen \\ University of Helsinki \\ minka.rissanen@helsinki.fi \\ Erika Löfström \\ University of Helsinki \\ erika.lofstrom@helsinki.fi
}

Keywords: ethical sensitivity, socialisation, undergraduate students, graduate students, educational science, psychology

\begin{abstract}
The study focuses on the ethical sensitivity of university students in light of their research ethics skills and the university as a learning environment. Eighty-seven students in the behavioural sciences (psychology and educational science) responded to a questionnaire that included three vignettes and measures of empathy, socialisation, and experiences of ethical aspects of the learning climate. The vignettes were designed to measure sensitivity to ethical issues in research. The relationship between socialisation into the practices of the profession and the institution and the ability to recognise ethical issues in research suggests that students who have already 'worked out' the norms and values for themselves have committed to these ethics and are willing to apply them in practice.
\end{abstract}

\section{Introduction}

One of the tasks of universities is to prepare their students to master the ethical standards of their professions and the related procedures (Strain, Barnett, \& Jarvis, 2009; Zucchero, 2008). An understanding of research ethics and professional ethics is an essential part of good science and the competence of university-trained professionals. Not all university graduates aspire to become researchers, but many will pursue careers in which they have to process and create new knowledge and utilise the methods and practices of research. In order to be able to evaluate research -based knowledge, graduates need not only methodological understanding, but also understanding of research ethics to assess the ethical basis of the knowledge created.

Disciplines differ in how they conceptualise and view ethics. Some disciplines may have few guidelines, whereas others (e.g., medicine) have a highly developed and complex ethical theory and a wide scope of literature related to research and professional ethics (Strain et al., 2009). This may contribute to difficulties in making general suggestions for what and how to teach in terms of professional and research ethics. Furthermore, discipline-specific research has been unable to pinpoint which features in the pedagogical practices promote ethical sensitivity (King \& Mayhew, 2002). Researchers (Clarkeburn, 2002b; Sirin, Brabeck, Santiani, \& Rogers-Serin, 2003) have proposed a skills-based approach to consider the appropriate contents and the activities for teaching and learning. Suggestions have been made as to what

The International Journal for Educational Integrity is available online at:

http://www.ojs.unisa.edu.au/journals/index.php//JEI/

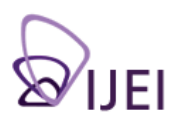


might be the most effective ways of teaching integrity and research ethics to university students. An infusion of ethics content throughout curricula has been proposed as the most effective way of teaching ethics-related content to university students; however, Sanders and Hoffman (2010) found only ambiguous support for this claim. Class discussions along with syllabi and course outlines that acknowledge academic integrity have been suggested as effective means of encouraging student learning about academic integrity and ethics (Gynnild \& Gotschalk, 2008). Also specific courses or interventions addressing research ethics have been proven successful (Burr \& King, 2012; Clarkeburn, 2002a; Fisher \& Kuther, 1997; Zucchero, 2008).

In addition to formal course work, learning also takes place in less formal encounters with faculty through observation and interaction (Kitchener, 1992). An ethical climate or culture (Ferguson, Masur, Olson, Ramirez, Robyn, \& Schmaling, 2007; Kalichman \& Friedman, 1992; Roberts, Kavussanu, \& Sprague, 2001) influences the willingness of members of the academic community to engage either in ethical research behaviour or unethical behaviour depending on how they interpret the prevailing norms. This indicates the importance of contextual variables in learning about academic integrity and ethical conduct in research. Van Hooft's (2009) proposal, namely, that ethics should be both the object and the context of teaching throughout higher education, is understandable in light of studies that pinpoint the influence of contextual variables on learning about integrity and ethics. Therefore, this study focuses on the university as a learning environment for developing sensitivity to ethical issues in a research context. In this study, the university learning environment is approached through contextual factors, such as students' experiences of the institutional climate and their perceived socialisation into the profession and the institution of study. We have also considered empathy as a personal aspect, which a number of researchers (e.g., Bebeau, Rest, \& Narvaez, 1999; Eisenberg, Cumberland, Guthrie, Murphy, \& Shepard, 2005; Sparks \& Hunt, 1998; Sadler, 2004; Weaver, 2007) have associated with ethical or moral sensitivity.

This study focuses on undergraduate and graduate psychology and educational science students' experiences of the university learning environment and the students' ability to identify ethical issues in research. There has been relatively little research on student learning of research ethics in the humanities and the social and behavioural sciences (see Wagner, Garner, \& Kawulich, 2011). This is striking considering that in these fields, especially the social and behavioural sciences, researchers often conduct research with human participants. When working with human participants, researchers run the risk of psychological and social harm, making it vital that the researcher adhere to ethical standards to protect the participants.

\section{Teaching and learning research ethics in the behavioural sciences}

In their extensive review of studies on the teaching of research methodology between 1997 and 2007, Wagner et al. (2011) identify only two studies that address the teaching of research ethics, namely, those by Brinthaupt (2002) and McGinn and Bosacki (2004). McGinn and Bosacki (2004) found that graduate students in educational science generally harboured many uncertainties and questions regarding research ethics and research work. To address these uncertainties, the authors suggested that research courses need to foster reflective researchers who consider research-related decisions in light of pragmatic, philosophical, ethical, and moral perspectives encompassing all aspects in the research process (i.e., research design, method, data analysis, dissemination).

More recently, Burr and King (2012) have reported on how reality television can be used successfully to teach students of psychology about ethical issues in research. Löfström (2012) found that participation in research and the experience of conducting research were related to a heightened awareness of ethical issues in research among students in one university psychology department. Similarly, Moyer and Franklin 
(2011) found that participation in research fostered an understanding of the science of psychology among undergraduate psychology students. Zucchero (2008) has shown that research ethics can be effectively taught in introductory psychology using combinations of lectures, case studies, codes of ethics, class discussions, and small group discussions. Also Fisher and Kuther (1997) found that the use of case studies improved the students' ability to detect ethical issues in research. However, Belshaw (2009) has questioned whether ethics courses are sufficient for instilling ethical behaviours unless the students are prone to ethical behaviour at the outset.

In addition to learning from the university's formal activities and course work, informal learning environments play a substantive role (see Kitchener, 1992). Anderson, Louis, and Earle (1994) found that the ethical environment of a university bears a relationship to the appearance of ethical misconduct. This suggests that members of an academic community adopt behavioural characteristics of the ethical environment in which they act. Contextual aspects and implicit learning must therefore be taken into account when examining teaching and learning research ethics in universities (see Kitchener, 1992).

\section{Ethical sensitivity, empathy, and socialisation in a research context}

\section{Ethical sensitivity}

The ability to recognise potential moral dilemmas in a situation is referred to as ethical sensitivity. Ethical sensitivity is a prerequisite for ethical thinking and behaviour (Bebeau, Rest, \& Yamoor, 1985). In the literature, the concept of moral sensitivity is often used, which we understand to be almost synonymous with ethical sensitivity. Ethical sensitivity does not necessarily require the presence of an actual ethical problem or conflict. Ethical dilemmas are typically amorphous in nature and it may not be immediately evident that the dilemma one faces is ethical (Butterfield, Trevino, \& Weaver, 2000; Robin, Reidenbach, \& Forrest, 1996). Ethical sensitivity is a critical step for activating ethical decision-making processes, because the interpretation of the situation sets the premises for the subsequent thinking process (Butterfield et al., 2000). Yet ethical sensitivity does not refer to the capacity to make morally justified decisions, resolve moral dilemmas, analyse concepts, draw conclusions, or provide justifications for action (Hébert, Meslin, \& Dunn, 1992). Without the recognition of ethical dimensions in a situation, it is impossible to begin to solve any ethical dilemmas, because without the recognition, the dilemma does not exist for the individual. It is impossible to move towards ethical decision-making without the recognition of the magnitude of the dilemma and the consequences of the decision (Clarkeburn, 2002a). Clarkeburn (2002b) has concluded that higher education may not be the most encouraging environment in terms of facilitating ethical sensitivity, but tailored interventions have been proven fruitful. To motivate students to learn about ethics and encourage their interest in developing ethical sensitivity, a studentcentered approach to teaching which facilitates group discussions has been deemed successful (Clarkeburn, Downie, \& Matthew, 2002).

Rest (1986a) depicts a four-step model for ethical decision-making and action: 1) detecting a dilemma, 2) resolving the dilemma, 3) prioritising an ethical solution, and 4) exhibiting the inner strength to do what is believed to be the right thing. The teaching of ethics generally revolves around the second step, i.e., resolving the dilemma. The fourth step involves personal values and morale. Rest's (1986a) model of ethical decision-making and action has been highly influential in the research on ethical and moral decision-making. The majority of the empirical research on ethics and morals focuses on the second and fourth steps of ethical decision-making (Butterfield et al., 2000).

Less attention has been given to the first step - an interpretive process in which the individual either recognises the ethical dilemma embedded in a situation or does not. 
However, some studies have been conducted, which focus on culture and ethnicity (Sirin, Rogers-Serin, \& Collins, 2010), or on a variety of professions or groups, such as marketing professionals and students (Sparks \& Hunt, 1998), children (Jordan, 2007), accounting students (Shawver \& Sennetti, 2009), and health care personnel (Baeroe \& Norheim, 2011). Prior research has also focused on the ethical sensitivity of professionals in the contexts of dentistry, social work, medicine, and leadership (see Jordan, 2007). Established measures for ethical sensitivity include the Defining Issues Test (DIT) (Rest, 1986b; see also review in King \& Mayhew, 2002), Dental Ethical Sensitivity Test (DEST) for dentistry students (Bebeau et al.,1985), and the McNeel (1994) moral sensitivity test. None of these specifically focus on ethical awareness in the context of research ethics.

\section{Socialisation}

Although ethical guidelines establish codes of conduct, rules for interaction and decision-making in the academic community may not be explicitly covered by these guidelines (see Ferguson et al., 2007). Instead, these rules are the very essence of what is learned through socialisation processes to communities and professions. Organisational socialisation refers to the processes by which individuals commit themselves to the values, norms and rules of a community and allow the individual gradually to claim membership in the organisation, group, or community (van Maanen, 1976). Some of these values and norms may be explicitly stated, for instance, in published guidelines or in the form of rules, but some are implicit and tacit in nature. Organisational socialisation has been found to have a positive relationship with ethical sensitivity (Sparks \& Hunt, 1998).

Professional socialisation, i.e., the processes by which individuals learn the norms and values of the profession (van Maanen, 1976), transcends organisational boundaries (Sparks \& Hunt, 1998). Professional socialisation is often initiated during studies and continues later on in the professions (Sparks \& Hunt, 1998). A positive relationship has been found between psychology students' professional socialisation and an awareness for ethical issues in a domain-transcending research ethics tasks (Löfström, 2012).

\section{Empathy}

Empathy has often been associated with ethical (or moral) sensitivity. Empathy is a universal reaction among humans that influences both sense and the cognitive process (Hoffman, 1981) and refers to an affective reaction to someone else's situation, i.e., placing oneself in someone else's position and feeling their emotions. Both a cognitive (perspective-taking) and an affective (emotional contagion) dimension are inherent in empathy. The cognitive understanding of someone else's situation is followed by an emotional reaction (Stiff, Dillard, Somera, Kim, \& Sleight, 1988). Definitions of ethical sensitivity have sometimes incorporated empathy (Eisenberg et al., 2005; Sadler, 2004). Bebeau et al. (1999) and Weaver (2007) associate empathy with the affective domain of ethical (moral) sensitivity.

Studies (Löfström 2012; Sparks \& Hunt, 1998) have found a positive relationship between the cognitive component of empathy, i.e., perspective-taking, and ethical sensitivity, suggesting that ethical sensitivity and ethical reasoning may be primarily cognitive functions. Myyry and colleagues found that perspective-taking contributed to more advanced stages of moral judgment, i.e., post-conventional thinking (Myyry, Juujärvi, \& Pesso, 2010). In addition to the cognitive component, there is some degree of choice inherent in empathy: Individuals can to a certain extent allow or block certain emotions (Claypool \& Molnar, 2011). Empathy appears to assist individuals in positioning themselves in ethical matters and to engage in ethical and responsible action (Claypool \& Molnar, 2011). 
Recognising the importance of ethical sensitivity in ethical thinking, the relationship of empathy with ethical sensitivity, and the role of the environment in which students learn, we posed the following research questions: 1) How well do undergraduate and graduate students in the behavioural sciences recognise ethical issues in research? 2) How are individual variables, i.e., field, study level, study progression, and empathy related to students' ability to recognise ethical issues in research? 3) How are contextrelated variables, i.e., socialisation and perceptions of the learning climate, related to students' ability to recognise ethical issues in research? 4) Do any of the individual or contextual variables predict students' ability to recognise ethical issues in research?

\section{Method}

\section{Participants and context}

The participants were graduate and undergraduate students in psychology and educational science at a large research-intensive university in Finland. The sample size was 87 . A request to participate in the research was sent out to the majority of the student body within psychology and educational science, i.e., to 971 students whose email addresses could be collected from the student register. The response rate was approximately $9 \%$. Of these, $91 \%(n=79)$ were female and $9 \%(n=8)$ male. Sixty-eight percent $(n=59)$ were students in educational science and $32 \%(n=28)$ were students in psychology. According to the University's statistics in 2011, there were 1,118 undergraduate and graduate students in educational science and psychology. Of these, $83 \%(n=925)$ were female and $17 \%(n=193)$ male; $63 \%(n=$ 710) were students in educational science, and $36 \%(n=408)$ were students in psychology. In light of these figures, the response rates in the two disciplines reflected those of actual student enrolment; however, gender distribution did not. With the limited number of male respondents, we did not attempt statistical analyses that compared males and females.

In the Finnish higher education system, studies for a bachelor's degree take three years, with an additional two years necessary for a master's degree. Students typically study for a master's degree. Of the respondents, $28(32 \%)$ studied at the bachelor's level (1-3 years of study), $28(32 \%)$ at the master's level (4-5 years of study), and $31(36 \%)$ had studied six years or more towards a master's degree. A bachelor's degree equals 180 credits (1 credit in the European Credit Transfer System equals approximately 27 hours of study), and a master's degree requires an additional 120 credits. Twenty-nine participants (33\%) had earned $40-180$ credits, 44 $(51 \%)$ had earned $181-300$ credits, and $14(16 \%)$ had earned more than 300 credits.

Students were informed about the study in a cover letter providing a link to the electronic survey. Participation was voluntary, and no incentives for participation were used.

\section{Measures}

\section{Vignettes measuring ethical sensitivity}

The research ethics competencies of students were examined here through the concept of ethical sensitivity. An approach in which students are asked to identify ethical dilemmas or breaches in domain-specific contexts was deemed suitable. One vignette was adapted from Zucchero (2008, see also Kitchener, 2000). This vignette depicted a research scenario involving children and endorsing undesired behaviours and was suitable for our target group. The other two vignettes designed for this study adhered to the same style as the one adapted from Zucchero, as follows:

Vignette 2: A researcher investigates university students' experiences of security in relationships. The method used is group interview. One of the participants contacts the researcher afterwards and says that he no longer 
wishes to participate in the study. The researcher concludes that because the informant has already given his consent and no single participant can be identified from the results, she will continue to use the participant's data. After the analyses, the researcher stores all data thinking that she may need the material later on.

Vignette 3: A researcher conducts research on project management in Company X. The researcher hopes to interview the company's employees. The interviews take place in a private office where the participants will be undisturbed. However, the researcher notices that many of the employees seem reserved, stressed, and even distressed as they respond to the researcher's questions. Some of them imply that participation in the research actually means lost work time, something that their superiors would not look upon favourably. The researcher finds that he repeatedly needs to encourage the employees to speak. In analysing the interviews, he concludes that there is a lot of room for improvement in the project management of Company $X$. The researcher is not specifically asked to lie about his findings, but the research contractor urges the researcher to report the findings selectively. The researcher does not want to refuse, because the contractor is a key stakeholder in his field.

The ethical issues weaved into Vignette 2 pertained to participants' right to withdraw, to confidentiality and data storage, to researching sensitivity issues and anonymity. The ethical issues in Vignette 3 pertained to maleficence (causing anxiety and adding to employees' workloads), maintaining anonymity and confidentiality, and dissemination/withholding of findings. As in Zucchero (2008), students were asked to identify three ethical issues in each vignette, adding up to a total of nine issues. For each ethical issue a student could earn one point in the analysis phase. Thus, a student could score $0-9$ on the three vignettes.

\section{Socialisation and empathy scales}

Socialisation and empathy were measured using two instruments developed by Sparks and Hunt (1998) to university students and a behavioural sciences context. Both measures were composed of two four-item sub-scales, namely, organisational socialisation and professional socialisation, and perspective taking and emotional contagion. The adaptation of the socialisation scales (see Löfström, 2012) included changing the disciplinary context and changes in verb tense to reflect the situation of someone practicing the profession in the future (as opposed to an already practicing professional). The following are examples of adapted items (changes to the original measure italicised):

- $\quad$ "I know what's considered (in)appropriate behaviour in my department" (organisational socialisation);

- $\quad$ "I know the things a good researcher in my field should and should not do" (professional socialisation);

- $\quad$ "I am usually able to understand why people do and say the things they do" (perspective taking); and

- $\quad$ "I hurt inside when I see others hurting" (emotional contagion).

A principal component analysis produced a solution that deviated from the theoretical assumption, whereby the two components would be socialisation into the profession and socialisation in the institution. Instead, the components were socialisation into the values of the profession and the institution, and socialisation into the practices of the profession and the institution. The items in the empathy measure loaded as expected, according to the theoretical rationale of the measure. 
Scales measuring student perceptions of ethical aspects of the institutional learning climate

Students' perceptions of the ethical aspects of their learning climate were measured through their perceptions of competition, solidarity, and individualism in their study environment. The following sub-scales (comprising seven items) from Anderson and Louis (1994) were included in the 18-item measure:

- "People have to compete for departmental resources" (competition);

- $\quad$ "There is a sense of solidarity among the students who enter the program at the same time" (solidarity); and

- $\quad$ "This department values individual research over collaborative research" (individualism).

The sub-scales measuring the dimensions of publications and obligations in the Anderson and Louis (1994) instrument were left out as the participants may not have had sufficient experience of these aspects. Undergraduate and graduate students in Finland rarely have obligations to faculty other than those directly involved in their studies, and students rarely collaborate on publications with faculty unless they are working on their doctoral dissertation. The Anderson and Louis (1994) solidarity and individualism sub-scales were complemented with 11 items (items $8,23,26,36,38$, $40,46,50,54,55,57$ in the original instrument) from the Undergraduate Ethical Climate Index by Schulte, Thompson, Hayes, Noble, and Jacobson (2001) in order to have more than one item with which to measure each sub-scale. The original instrument by Anderson and Louis (1994) measures solidarity and individualism with one item each, however, individual items could introduce considerable random measurement error (see Nunnally \& Bernstein, 1994). The following are sample items drawn from the Undergraduate Ethical Climate Index to complement the two one-item scales:

- "Students are attentive to their peers during class" (solidarity); and

- $\quad$ "Students reinforce and encourage one another" (individualism, reverse).

A principal component analysis of the measure for ethical aspects of the learning climate turned out differently than expected based on the theoretical construction of the measure. Instead of the components of competition, solidarity, and individualism, the analysis produced a positive and a negative ethical climate component.

\section{Background variables}

Other variables included in the study were age, field of study, and progression in the studies.

\section{Reliability of measures and statistical analyses}

The measurement instruments and the vignette adapted from Zucchero (2008) were translated from English into Finnish and back-translated to English to ensure the validity of the translations.

Sub-scales and their Cronbach alpha coefficients are provided in Table 1. Alpha coefficients ranged from .63 to .81 . Nunnally (1978), for instance, has proposed .70 as a cut-off point, but others (e.g., Schmitt, 1996) have suggested that lower alpha levels in short measurement instruments may be acceptable. In our case, the measurement instruments were relatively short. The socialisation and empathy scales loaded on two components with four items each, and the climate measure loaded on two components with ten and eight items each. 
Table 1:

Cronbach alpha coefficients and descriptive statistics for the sub-scales

\begin{tabular}{|l|c|c|}
\hline Component & $\boldsymbol{\alpha}$ & $\mathbf{M}(\mathrm{SD})$ \\
\hline Socialisation to values & .75 & $3.7(0.8)$ \\
\hline Socialisation to practices & .63 & $3.6(0.7)$ \\
\hline Perspective taking & .72 & $4.3(0.5)$ \\
\hline Emotional contagion & .70 & $3.7(0.7)$ \\
\hline Positive learning climate & .77 & $3.7(0.6)$ \\
\hline Negative learning climate & .81 & $2.5(0.6)$ \\
\hline
\end{tabular}

Statistical analyses included principal components analysis, correlations, T-test, analysis of variance, and regression analysis.

\section{Results}

Recognition of ethical issues in a research context

To answer the first research question of how well undergraduate and graduate students in the behavioural sciences recognise ethical issues in research, we scored the students' responses on the three vignettes. The scores varied from zero to three, but overall, students recognised at least half of the ethical issues (1.53 in the third vignette, and more in the other two). The standard deviations in the vignette scores are quite high, which indicates a large variety in the students' scores (Table 2).

Table 2:

Student scores on the three vignettes

\begin{tabular}{|l|c|c|}
\hline Vignette & Score range & M (SD) \\
\hline 1 & $0-3$ & $1.81(0.87)$ \\
\hline 2 & $0-3$ & $1.60(0.68)$ \\
\hline 3 & $0-3$ & $1.53(0.67)$ \\
\hline Total & $0-9$ & $4.93(1.56)$ \\
\hline
\end{tabular}

Individual and contextual variables and their relationship to students' ability to recognise ethical issues in research

In order to answer the second question, we analysed the relationship between students' ability to recognise ethical issues in research and the field of study, progression in studies, and empathy. T-tests indicated that there were statistically significant differences nor between students in educational science and those in psychology, neither between students at the undergraduate and graduate level. An ANOVA indicated that there was no statistically significant relationship between students' ability to recognise ethical issues in research and the progression of studies (number of credits earned). The relationship between students' perceived empathy and their ability to recognise ethical issues in research was examined with Pearson's correlation coefficient. The results showed no statistically significant relationship between these variables.

To answer the third research question on how contextual variables are related to students' ability to recognise ethical issues in research, we examined the students' experiences of socialisation and their learning climate (in terms of its ethical characteristics) (using Pearson's correlation coefficient). The relatively high mean (3.7 
on a scale from 1 to 5 , see Table 1) suggests that the students perceived their learning climate to be primarily positive. However, there was no statistically significant relationship between students' perceptions of the institutional climate and their ability to recognise ethical issues in research; however, there were statistically significant relationships between students' perceived socialisation and their ability to recognise ethical issues in research in the third vignette (Table 3). This relationship was further examined with regression analysis (Research question 4) (Table 4). In the regression model $\left(F[2,83]=4.955, p<.01, R^{2}=.09\right)$, a higher socialisation into practices predicted a higher score in the third vignette; however the effect size was relatively small (Cohen, 1988).

Table 3:

Correlations between socialisation components and vignettes

\begin{tabular}{|l|c|c|c|}
\hline Socialisation & Vignette 1 & Vignette 2 & Vignette 3 \\
\hline Socialisation to values & .015 & .039 & $.222^{*}$ \\
\hline Socialisation to practices & .113 & .191 & $.323^{\star *}$ \\
\hline
\end{tabular}

${ }^{* *} p<0.01,{ }^{*} p<0.05$

Table 4:

Regression model for the socialisation components

\begin{tabular}{|l|c|c|c|c|c|}
\hline Socialisation & $\mathbf{B}$ & $\boldsymbol{\beta}$ & $\mathbf{t}$ & $\mathbf{p}$ & Tolerance \\
\hline Socialisation to values & .058 & .068 & .550 & $\mathrm{~ns}$. & .713 \\
\hline Socialisation to practices & .280 & .287 & 2.322 & $<.05$ & .713 \\
\hline
\end{tabular}

\section{Discussion}

\section{Students' ethics competencies}

The students' sensitivity to ethical issues in research can be considered relatively good, with on average at least half of the issues identified. It appeared that most of the students had put a fair amount of effort into the vignette tasks, despite the fact that these required more active processing on their part than the conventional measurement scales. Overall, the students scored best on the first vignette, second best on the second vignette, and least on the third vignette. The presence of harm or the potential violation of behavioural norms triggers moral awareness (Reynolds, 2006), and it might be that the first vignette most clearly signalled a violation of moral norms, while the second vignette signalled the possibility of harm. The presence of harm or violation may have been the least obvious in the third vignette, and in this sense the third vignette may have worked best to distinguish between students with lower and higher levels of ethical sensitivity. However, as the research participants only represent roughly $10 \%$ of the local population, the result of the regression analysis must be viewed as indicative of a tendency in a rather selected group of students.

On the one hand, it is encouraging that the students voluntarily took the time to consider the ethical issues in research. On the other hand, it may be worrying that a very small number of students contacted about the survey replied. This suggests that there is a relatively small number of students who are eager to engage in ethical thinking and problem-solving, and as they do so, they develop functional tools with which to sort out ethical issues. The majority of the students may not find ethical issues in research particularly interesting or important, and opt out of opportunities to think about such questions unless they really have to. 
There were no statistically significant relationships between ethical sensitivity, empathy, and experiences of ethical aspects in the learning climate. Based on prior research (Löfström, 2012; Sparks \& Hunt, 1998), a relationship between empathy and ethical sensitivity had been expected. The students may have approached the vignettes from a more rational or analytical perspective, since such an approach may be encouraged in learning about research and methodology in their studies. We suspect that students are not generally encouraged to approach research-related content from an empathy perspective.

The students in psychology and educational science did not differ in terms of their ethics competencies. Although the students study in different programmes, they all study in the same faculty, and are likely to be exposed to a relatively unified teaching and learning culture. Age did not have a relationship with ethical sensitivity, which corroborates findings in prior research (see Löfström, 2012; Sparks \& Hunt, 1998).

The lack of a relationship between the progression of studies and the recognition of ethical issues in research is not straightforward. One may have expected ethical sensitivity to increase as the studies progress; however, prior research (Sparks \& Hunt, 1998) suggests that students' ethical sensitivity is greatest at the beginning of their studies, after which it gradually declines. Hébert and colleagues (1992) have demonstrated a decrease in ethical sensitivity in the third and fourth years of study, while Sanders and Hoffman (2010) found that graduate students in their final term exhibited less ethical sensitivity than their first-year peers. Researchers have suggested that an emphasis on ethical principles may blur the line between rules and ideals, making it difficult for some students to determine when an issue is ethical in nature (Hébert et al., 1992; Sanders \& Hoffman, 2010). Another reason offered by Sparks and Hunt (1998) is that professional norms and standards provide a framework for interpreting situations. Socialisation into the norms and values of a profession thus decreases an individual's personal evaluation of a situation.

\section{Learning environment}

Experiences of ethical aspects of the learning climate were not related to ethical sensitivity, reinforcing the interpretation that one develops ethical sensitivity irrespective of whether one's experiences of the ethical climate are positive or negative (e.g. Löfström, 2012). Anderson et al. (1994) found that students who collaborated most closely with faculty were also the ones most frequently exposed to unethical behaviour, but this does not automatically mean that the students themselves engaged in unethical behaviour. They may have been sensitised to ethical issues, and in this sense, hypothetically there could be a positive relationship between the students' ethical sensitivity and the negative experiences of ethical aspects of the learning climate. To establish the existence of such a relationship more research is required.

The loading of the socialisation items deviated from past studies (Löfström 2012; Sparks \& Hunt, 1998), resulting in a 'Norms' and a 'Practices' component instead of socialisation into the profession and into the organisation. In our analyses, professional or organisational norms were differentiated from professional or organisational practices. This suggests that students who have not yet entered a profession or who have not worked in organisations do not distinguish between these two domains. Socialisation into practices predicted ethical sensitivity in the third vignette suggesting that students who have already 'worked out' the norms and values for themselves (the inductive process) have committed themselves to these values and are willing to apply them in practice (cognitive tools, see Andorno, 2012). This finding emphasises the importance of contextual aspects and implicit learning.

\section{Reliability and replication}

We would like to remind readers to exercise caution in reading our interpretations of the findings. First, the variable "Socialisation into professional and institutional 
practices," which appeared to be a statistically significant predictor of students' ability to recognise ethical issues in research, had the lowest reliability of the three variables measured. On the other hand, with a four-item scale it is possible that measurement length (in this case very short) deflated its reliability index. Second, the sample size was relatively small and the response rate low, which indicates that the students who decided to participate in the research are a select group. We suspect that the students who responded to the questionnaire are likely to be more interested in ethical issues than students in general, and their responses are unlikely to reflect those of the wider group. Third, education systems and university contexts can vary greatly across countries and continents, thus making replication of single-institution studies, such as this one, challenging. However, the Bologna Process has resulted in the convergence of European higher education (Voegtle, Knill, \& Dobbins, 2011), and thus the study may provide an impetus, especially for other research-intensive universities, to examine their learning environments in terms of how these promote research ethics and integrity among students.

\section{Suggestions for further research.}

Further research is needed on students' conceptions of the ethical issues that they identified solving the vignette tasks, i.e. how do students reason about ethical issues? How do the students justify their views? And how do students experience whether their learning environments support the learning of research ethics? In other words, what are the pedagogical designs that support their learning? A third question warranting further investigation is the ethical sensitivity and the experiences of learning environments of those students who failed to respond to the questionnaire. Their competencies and experiences could raise altogether different educational concerns.

\section{References}

Anderson, M. S., \& Louis, K. (1994). The graduate student experience and subscription to the norms of science. Research in Higher Education, 35, 273299.

Anderson, M. S., Louis, K. S., \& Earle, J. (1994). Disciplinary and departmental effects on observations of faculty and graduate student misconduct. Journal of Higher Education, 65, 331-350.

Andorno, R. (2012). Do our moral judgements need to be guided by principles? Cambridge Quarterly of Healthcare Ethics, 21, 457-465.

Baeroe, K., \& Norheim, O. F. (2011). Mapping out structural features in clinical care calling for ethical sensitivity: A theoretical approach to promote ethical competence in healthcare personnel and clinical ethical support services (CESS). Bioethics, 25, 394-402.

Bebeau, M., Rest, J., \& Narvaez, D. (1999). Beyond the promise: A perspective on research in moral education. Educational Researcher, 28, 18-26.

Bebeau, M. J., Rest, J. R., \& Yamoor, C. M. (1985). Measuring dental students' ethical sensitivity. Journal of Dental Education, 49, 225-235.

Belshaw, C. (2009). The teacher's perspective. Teaching ethics and professional ethics in universities. In J. Strain, R. Barnett, \& P. Jarvis (Eds.), Universities, ethics and professions. Debate and scrutiny (pp. 113-125). New York: Routledge.

Brinthaupt, T. M. (2002). Teaching research ethics: Illustrating the nature of researchers-IRB relationship. Teaching of Psychology, 29, 243-245.

Burr, V., \& King, N. (2012). 'You're in cruel England now!': Teaching research ethics through reality television. Psychology Learning \& Teaching, 11, 22-29.

Butterfield, K. D., Treviño, L. K., \& Weaver, G. R. (2000). Moral awareness in business organizations: Influences of issue-related and social context factors. Human Relations, 53, 981-1018.

Clarkeburn, H. (2002a). A test for ethical sensitivity in science. Journal of Moral Education, 31, 439-453. 
Clarkeburn, H. (2002b). The aims and practice of ethics education in an undergraduate curriculum: Reasons for choosing a skills approach. Journal of Further and Higher Education, 26, 307-315.

Clarkeburn, H., Downie, J. R., \& Matthew, B. (2002). Impact of an ethics programme in a life sciences curriculum. Teaching in Higher Education, 7, 65-79.

Claypool, T., \& Molnar, T. (2011). Empathy and ethics: A conversation between colleagues. Our Schools, Our Selves, 20, 175-185.

Cohen, J. (1988). Statistical power analysis for the behavioral sciences (2nd ed.). Hillsdale, NJ: Lawrence Erlbaum.

Eisenberg, N., Cumberland, A., Guthrie, I. K., Murphy, B. C., \& Shepard, S. A. (2005). Age changes in prosocial responding and moral reasoning in adolescence and early adulthood. Journal of Research on Adolescence, 15, 235-260.

Ferguson, K., Masur, S., Olson, L., Ramirez, J., Robyn, E., \& Schmaling, K. (2007). Enhancing the culture of research ethics on university campuses. Journal of Academic Ethics, 5, 189-198.

Fisher, C. B., \& Kuther, T. L. (1997). Integrating research ethics into the introductory psychology course curriculum. Teaching of Psychology, 24, 172-175.

Gynnild, V., \& Gotschalk, P. (2008). Promoting academic integrity at a Midwestern University: Critical review and current challenges. International Journal for Educational Integrity, 4, 41-59.

Hébert, P. C., Meslin, E. M., \& Dunn, E. V. (1992). Measuring the ethical sensitivity of medical students: A study at the University of Toronto. Journal of Medical Ethics, 18, 142-147.

Hoffman, M. L. (1981). Is altruism part of human nature? Journal of Personality and Social Psychology, 40, 121-137.

Jordan, J. (2007). Taking the first step towards a moral action: A review of moral sensitivity across domains. Journal of Genetic Psychology, 168, 323-359.

Kalichman, M. W., \& Friedman, P. J. (1992). A pilot study of biomedical trainees' perceptions concerning research ethics. Academic Medicine, 67, 769-775.

King, P. M., \& Mayhew, M. J. (2002). Moral judgment development in higher education: Insights from the Defining Issues Test. Journal of Moral Education, $31,247-270$.

Kitchener, K. (1992). Psychologist as teacher and mentor: Affirming ethical values throughout the curriculum. Professional Psychology: Research and Practice, 23, 190-195.

Kitchener, K. (2000). Foundations of ethical practice, research, and teaching in psychology. Mahwah, NJ: Lawrence Erlbaum Associates.

Löfström, E. (2012). Students' ethical awareness and conceptions of research ethics. Ethics \& Behavior, 22(5), 349-361.

McGinn, M., \& Bosacki, S. L. (2004). Research ethics and practitioners: Concerns and strategies for novice researchers engaged in graduate education. Forum: Qualitative Social Research, 5, Art. 6.

McNeel, S. P. (1994). College teaching and student moral development. In J. R. Rest \& D. Narvaéz (Eds.), Moral development in the professions: Psychology, and applied ethics (pp. 1-26). Hillsdale: Lawrence Erlbaum.

Moyer, A., \& Franklin, N. (2011). Strengthening the educational value of undergraduate participation in research as part of a psychology department subject pool. Journal of Empirical Research on Human Research Ethics, 6, 7582.

Myyry, L., Juujärvi, S., \& Pesso, K. (2010). Empathy, perspective taking and personal values as predictors of moral schemas. Journal of Moral Education, 39, 213233.

Nunnally, J. C. (1978). Psychometric theory. New York: McGraw-Hill.

Nunnally, J. C., \& Bernstein, I. H. (1994). Psychometric theory (3rd ed.). New York: McGraw-Hill. 
Rest, J. R. (1986a). Moral development: Advances in research and theory. New York: Praeger.

Rest, J. R. (1986b). DIT: Manual for the Defining Issues Test. Minneapolis, MN: University of Minnesota Center for the Study of Ethical Development.

Reynolds, S. J. (2006). Moral awareness and ethical predispositions: Investigating the role of individual differences in the recognition of moral issues. Journal of Applied Psychology, 91, 233-243.

Roberts, G. C., Kavussanu, M., \& Sprague, R. L. (2001). Mentoring and the impact of the research climate. Science and Engineering Ethics, 7, 525-537.

Robin, D. P., Reidenbach, R. E., \& Forrest, P. J. (1996). The perceived importance of an ethical issue as an influence on the ethical decision-making of ad managers. Journal of Business Research, 35, 17-28.

Sadler, T. D. (2004). Moral sensitivity and its contribution to the resolution of socioscientific issues. Journal of Moral Education, 33, 339-358.

Sanders, S., \& Hoffman, K. (2010). Ethics education in social work: Comparing outcomes of graduate social work students. Journal of Social Work Education, 46, 7-22.

Schulte, L. E., Thompson, F., Hayes, K., Noble, J., \& Jacobs, E. (2001). Undergraduate faculty and student perceptions of the ethical climate and its importance in retention. College Student Journal, 34, 565-576.

Shawver, T. J., \& Sennetti, J. T. (2009). Measuring ethical sensitivity and evaluation. Journal of Business Ethics, 88, 663-678.

Sirin, S. R., Brabeck, M. M., Santiani, A., \& Rogers-Serin, L. (2003). Validation of a measurement of ethical sensitivity and examination of the effects of previous multicultural and ethics courses on ethical sensitivity. Ethics \& Behavior, 13, 221-235.

Sirin, S. R., Rogers-Serin, L., \& Collins, B. A. (2010). A measure of cultural competence as an ethical responsibility: Quick-Racial and Ethical Sensitivity Test. Journal of Moral Education, 39, 49-64.

Schmitt, N. (1996). Uses and abuses of Coefficient Alpha. Psychological Assessment, $8,350-353$

Sparks, J. R., \& Hunt, S. D. (1998). Marketing researcher ethical sensitivity: Conceptualization, measurement, and exploratory investigation. Journal of Marketing, 62, 92-109.

Stiff, J. B., Dillard J. P., Somera, L., Kim, H., \& Sleight, C. (1988). Empathy, communication and prosocial behavior. Communication Monographs, 55, 198213.

Strain, J., Barnett, R., \& Jarvis, P. (2009). Introduction. In J. Strain, R. Barnett \& P. Jarvis (Eds.). Universities, ethics and professions. Debate and scrutiny (pp. 19). New York: Routledge.

Van Hooft, S. (2009). Dialogue, virtue and ethics. In J. Strain, R. Barnett \& P. Jarvis (Eds.). Universities, ethics and professions. Debate and scrutiny (pp. 81-93). New York: Routledge.

Van Maanen, J. (1976). Breaking in: Socialization to work. In R. Dubin (Ed.). Handbook of work, organization and society (pp. 67-130). Rand McNally.

Voegtle, E., Knill, C., \& Dobbins, M. (2011). To what extent does transnational communication drive cross-national policy convergence? The impact of the Bologna-process on domestic higher education policies. Higher Education, 61, 77-94.

Wagner, C., Garner, M., \& Kawulich, B. (2011). The state of the art of teaching research methods in the social sciences: Toward a pedagogical culture. Studies in Higher Education, 36, 75-88.

Weaver, K. (2007). Ethical sensitivity: State of knowledge and needs for further research. Nursing Ethics, 14, 141-155.

Zucchero, R. A. (2008). Can psychology ethics effectively be integrated into introductory psychology? Journal of Academic Ethics, 6, 245-257. 


\section{Acknowledgements}

The work is part of the project "Teaching and Learning Academic Integrity in the Social Sciences: A university pedagogical approach", which is supported by the Academy of Finland under Grant 252813 to the second author. A prior shorter version of this paper entitled "The University as a Learning Environment for Research Ethics" is to appear in Integrity in 2015 in the Global Research Arena, edited by Nicholas H. Steneck, Melissa S. Anderson, Sabine Kleinert, and Tony Mayer (World Scientific). The authors would like to thank Dr. Kirsi Pyhältö and Professor Sari Lindblom-Ylänne for their valuable comments during the research process, and the two anonymous reviewers for their helpful comments on an earlier draft.

\section{About the authors}

Minka Rissanen currently pursues master's studies at the Faculty of Law, University of Helsinki. Her interests include diverse issues concerning ethics in university teaching, research, and law. She is keen on integrating different fields in an interdisciplinary discussion.

Erika Löfström is an Academy Research Fellow at the Centre for Research and Development of Higher Education, University of Helsinki. Erika's research interests include academic integrity and research ethics, and university teaching and learning. She leads a research project funded by the Academy of Finland focusing on the teaching and learning of academic integrity in social and behavioural sciences. 